\title{
Inhibition of ROCK-Myosin II Signaling Pathway Enables Culturing of Human Pluripotent Stem Cells on Microcarriers Without Extracellular Matrix Coating
}

\author{
Allen Kuan-Liang Chen, PhD, Xiaoli Chen, BEng, Yu Ming Lim, BEng, \\ Shaul Reuveny, PhD, and Steve Kah Weng Oh, PhD
}

Large quantities of human pluripotent stem cells (hPSCs) needed for therapeutic applications can be grown in scalable suspended microcarrier cultures. These microcarriers are coated with animal or human extracellular matrix (ECM) proteins to promote cell growth and maintain pluripotency. However, the coating is costly for large-scale cultures and it presents safety risks. This study demonstrates that hPSCs can be propagated on noncoated positively charged cellulose microcarriers in a serum-free medium containing the ROCK inhibitor, (Y27632) or myosin inhibitor, Blebbistatin. In the presence of these two inhibitors, myosin phosphatase 1 and myosin light chain 2 were dephosphorylated suggesting that reduced myosin contractility is responsible for hPSC survival and growth on ECM coating-free microcarriers. Cells propagated on the noncoated microcarriers for 12 passages maintained their pluripotency and karyotype stability. Scalability was demonstrated by achieving a cell concentration of $2.3 \times 10^{6}$ cells $/ \mathrm{mL}$ with 11.5 -fold expansion (HES-3) in a 100-mL spinner flask. The differentiation capability of these cells toward three primary lineages is demonstrated via in vitro embryoid bodies and in vivo teratoma formations. Moreover, the directed differentiation to polysialylated neuronal cell adhesion molecule-positive (PSA-NCAM +) neural progenitors produced high cell concentrations $\left(9.1 \pm 1.2 \times 10^{6}\right.$ cells $/ \mathrm{mL}$ ) with a cell yield of $412 \pm 77$ neural progenitor cells per seeded HES-3 and a PSA-NCAM expression level of $91 \pm 1.1 \%$. This defined serum- and coating-free scalable microcarrier culturing system is a safer and less expensive method for generating large amounts of hPSCs for cell therapies.

\section{Introduction}

T HE PROSPECT OF human pluripotent stem cells (hPSCs), including embryonic (hESCs) and induced stem cells (hiPSCs), in the field of regenerative medicine is mostly dependent on their self-renewal ability and their potential to differentiate into multiple cell types from the three germ layers: ectoderm, endoderm, and mesoderm. ${ }^{1-3}$ One of the challenges in using hPSCs for cell therapy is the development of a defined xeno-free and scalable culturing system.

hPSCs are traditionally cultured on feeder cells (e.g., mouse embryonic fibroblasts), which provide a microenvironment for maintaining pluripotency. Over the years, hESC cultures have developed from coculturing with feeder layers to feeder-free Matrigel-coated cultures. ${ }^{4,5}$ However, Matrigel consists of undefined mouse-derived components, which cannot be used in regenerative medicine due to safety issues. With this in mind, research groups have been striving to establish new methods of culturing hPSCs in chemically defined and xeno-free conditions. Matrigel was replaced by defined extracellular matrix (ECM) proteins like mousederived $^{6}$ or human recombinant laminin, ${ }^{7,8}$ human plasma- derived ${ }^{9}$ or recombinant vitronectin, ${ }^{10}$ and ECM (bone sialoprotein, vitronectin)-derived peptides. ${ }^{11}$ Interestingly, a study by Harb et al. ${ }^{12}$ reported that the addition of Rhoassociated kinase (ROCK) inhibitor, Y27632, into the serumfree medium (mTeSR1) enables the cultivation of hESC lines H1, BGN1, and H9 on poly-D-lysine-coated nontissue culture plates. This finding was later replicated by using the myosin inhibitor, Blebbistatin. ${ }^{13}$ hPSCs cultured in these conditions maintained pluripotency both in vivo and in vitro. ${ }^{12,13}$ The underlying roles of ROCK and myosin in hPSC adhesion and growth have not yet been fully clarified. It was suggested that the ROCK inhibitor prevented apoptosis and modulated cytoskeleton contraction thereby promoting hPSC survival and attachment on to surfaces. ${ }^{14}$

Two-dimensional (2D) tissue culture platforms have been used for generation of hPSCs. However, in clinical applications, where the cell dosage as high as $5 \times 10^{9}$ cardiomyocytes is required to treat myocardial infarction, ${ }^{15}$ mass production using the $2 \mathrm{D}$ platform is impractical. ${ }^{16}$ To meet this requirement, microcarrier technology for hPSC expansion provides a large surface area for cells to grow in scalable, suspension bioreactors. hPSCs cultured on microcarriers

Stem Cell Group, Bioprocessing Technology Institute, Agency for Science, Technology and Research (A*STAR), Singapore, Singapore. 
grow as cell-microcarrier aggregates and not as monolayers. In the initial step of seeding, cells attach and spread on the microcarrier surface; thereafter, several microcarriers join together generating aggregates composed of microcarriers and cells. ${ }^{17}$ Several research groups have demonstrated the feasibility of using this platform for culturing hPSCs in suspended cultures using ECM protein-coated microcarriers. ${ }^{17-}$ 23 The microcarrier platform is proven to be superior to the 2D tissue culture plates in terms of cell growth, robustness, and scalability without compromising pluripotency and karyotype stability of hPSCs. hPSCs cultured on microcarriers yielded between $2.2 \times 10^{6}$ and $6.1 \times 10^{6}$ cells $/ \mathrm{mL}$ in stirred bioreactors with 15-20-fold expansion. ${ }^{17,19-21}$ These levels are significantly higher than hPSCs cultured on 2D tissue culture plates. ${ }^{19,21,24}$ Our group has developed a cylindrical microcarrier platform based on cellulose matrix derivatized with diethylaminoethyl (DEAE) tertiary amine positively charged groups (DE-53, Whatman). ${ }^{17,19}$ The platform enables the expansion of hPSCs to high cell densities (up to $6.1 \times 10^{6}$ cells $/ \mathrm{mL}$ ) as well as in situ neural differentiation sequentially. ${ }^{21}$ Large quantities of polysialylated neuronal cell adhesion molecule-positive (PSA$\mathrm{NCAM}+$ ) neural progenitor cells (NPCs) of $8.4 \times 10^{6}$ cells / $\mathrm{mL}$ were generated with yields of 333-371 NPCs per seeded hPSC. ${ }^{21}$

Similar to the 2D culture platform, Matrigel coating on microcarriers is essential for supporting long-term hPSC growth, while maintaining pluripotency. ${ }^{17,19}$ hPSC s cultured on Matrigel-coated microcarriers exhibited 1.9-18 times higher cell concentrations and higher pluripotency than noncoated ones. ${ }^{19}$ Chen et al. examined seven different ECM proteins and identified laminin as a suitable candidate to replace Matrigel, for microcarrier coating. ${ }^{19}$ A later study by Heng et al. demonstrated that laminin- or vitronectin-coated microcarriers can support hPSC propagation in the serumfree medium. ${ }^{22}$ Both laminin- and vitronectin-coated microcarrier cultures exhibited similar cell growth profiles, consistently high expression ( $>90 \%$ ) of pluripotent markers, maintenance of karyotypic normality, and retained the ability to differentiate into lineages of all three germ layers. ${ }^{22}$

Using ECM proteins for microcarrier coating can be problematic since they may contain animal-derived components (Matrigel or mouse laminin) and are expensive (recombinant or plasma-purified human vitronectin, or recombinant human laminin $(511,521)$. In this study, we demonstrate for the first time that by adding either the ROCK inhibitor (Y27632) or Blebbistatin, hPSCs can be cultivated on uncoated positively charged DEAE cellulose microcarriers (DE-53) in a serum-free medium. Both hESCs and hiPSCs can be propagated in this system for multiple passages exhibiting high cell concentrations, while maintaining high levels of pluripotent markers and stable karyotypes. Differentiation capability was demonstrated by directed differentiation to NPCs. Scalability of the culture was demonstrated in 100-mL spinner flasks. We observed that dephosphorylation of myosin phosphatase 1 and myosin light chain 2 occurred in the presence of these two inhibitors, suggesting that reduced myosin contractility is responsible for hPSC growth on noncoated microcarriers.

This defined ECM-free, scalable microcarrier culturing system can serve as a safe and less expensive method for generating large quantities of hPSCs for clinical therapies.

\section{Materials and Methods}

\section{Cell culture}

The human embryonic stem cell line HES-3 (ES Cell International) and H7 (WiCell Research Institute, Inc.) and hiPSCs (IMR90; kindly provided by James Thomson ${ }^{25}$ ) were used in this study. All cultures were maintained on Matrigel (BD Bioscience)-coated tissue culture plates (Becton Dickson Lab ware). The serum-free medium (SFM), STEMPRO ${ }^{\circledR}$ hESC SFM (Life Technologies) was used for propagation of HES-3, whereas hESC H7 and hiPSCs (IMR90) were maintained on mTeSR ${ }^{\mathrm{TM}} 1$ (STEMCELL Technologies). Details on the coating procedure and subculturing are described in a previous publication. ${ }^{26}$

\section{Cultivation of hPSCs on microcarriers}

Positively charged cellulose-based cylindrical microcarriers (DE-53; Whatman) were used in this study. Details on Matrigel coating of the microcarriers and cultivation of hPSCs on microcarriers in static and spinner cultures were described previously. ${ }^{19,21,27}$ Briefly, for microcarrier coating, $5 \mathrm{mg}\left(4.2 \times 10^{4}\right.$ particles $/ \mathrm{mg}$ and $\left.6.8 \mathrm{~cm}^{2} / \mathrm{mg}\right)$ of microcarriers were mixed with $1 \mathrm{~mL}$ of a diluted Matrigel solution (1:30) in an ice-cool knockout (KO) medium and incubated overnight in $4^{\circ} \mathrm{C}$ on an orbital shaker. ${ }^{19}$ For stationary cultures, hPSC cultures were enzymatically harvested from confluent Matrigel-coated tissue culture plates (Accutase; PAA Laboratories) for HES-3 or $1 \mathrm{mg} / \mathrm{mL}$ Dispase (STEMCELL Technologies) for $\mathrm{H} 7$ and hiPSCs (IMR90). Accutase-treated cells generate single-cell suspension, whereas Dispase treatment resulted in small cell aggregates (Ø 200-300 $\mu \mathrm{m}$ ). These cells were seeded on $4 \mathrm{mg}$ / $\mathrm{mL}$ microcarriers (Matrigel-coated or noncoated) in six-well plates (Ultra-Low-attachment plate; Corning) at $2 \times 10^{5}$ cells $/ \mathrm{mL}\left(7.35 \times 10^{3}\right.$ cells $/ \mathrm{cm}^{2}$ and 1.2 cells/particle $)$. The plates were placed on an orbital shaker in a $37^{\circ} \mathrm{C}$ humidified incubator for $2 \mathrm{~h}$ at $110 \mathrm{rpm}$ to support cell attachment to microcarriers. Afterward, they were kept in a static condition for 7 days. Subculturing of microcarrier culture was done via gentle mechanical breakage of microcarriercell aggregates into uniform size ( $\varnothing 200-300 \mu \mathrm{m})$ with repetitive pipetting. ${ }^{27}$

The scalability of microcarrier culture was demonstrated using 100-mL spinner flasks (Bellco Cat. No. 1965-00100). The mechanically dissociated static microcarrier culture was seeded at viable cell concentrations of $4 \times 10^{5}$ cells $/ \mathrm{mL}$ to the spinner flask having $200 \mathrm{mg}$ of DE-53 microcarriers in a $25 \mathrm{~mL}$ medium. After seeding, the spinner flask culture was agitated at $25 \mathrm{rpm}$ for $2 \mathrm{~h}$. After 1 day in static condition, the culture volume was increased to $50 \mathrm{~mL}$ as the final working volume and continuous agitation was applied at $25 \mathrm{rpm}$.

For obtaining single-cell suspension, $5 \mathrm{~mL}$ of the cellmicrocarrier aggregate culture was washed two times with phosphate-buffered saline (PBS) by decantation. Then, $0.5 \mathrm{~mL}$ of TrypLE ${ }^{\mathrm{TM}}$ Express (Life Technologies) was added. After $5 \mathrm{~min}$ of incubation with occasional mixing, $3 \mathrm{~mL}$ of PBS was added and cells were gently dislodged from the microcarriers by pipetting. The single cells were separated from microcarriers via sieving through a $40-\mu \mathrm{m}$ cell strainer (BD Biosciences). Cell viability of more than $90 \%$ and harvesting efficiency of more than $70 \%$ were achieved. 
For both stationary and spinner culture, $80 \%$ of the medium was exchanged daily by letting the aggregates settle and removing the media. Viable cell counts were determined using NucleoCounter (NC-100; ChemoMetec A/S). ROCK inhibitor, Y27632 (Calbiochem) and Blebbistatin (SigmaAldrich) were added daily at the specified concentrations to the noncoated microcarrier cultures.

\section{Analysis of pluripotency}

To evaluate the expression level of pluripotent markers (Oct4, Tra-1-60, and mAb84 ${ }^{28}$ ), hPSCs on microcarriers were dissociated into single cells as described above. Thereafter, cells were immunostained and analyzed for expression of pluripotent markers using flow cytometry as described previously. ${ }^{17,19}$ The mAb84 antibody recognizes an extracellular domain Podocalyxin-like protein 1, which is expressed only in undifferentiated hPSCs. ${ }^{28}$

For immunostaining, microcarrier-cell aggregates were plated on a Matrigel-coated tissue culture dish for 1 day to allow cell attachment. After fixing with $4 \%$ paraformaldehyde, they were stained with 4',6-diamidino-2-phenylindole and mouse primary antibodies for Oct4. Alexa-fluor ${ }^{\circledR} 488$ conjugated $\mathrm{F}\left(\mathrm{ab}^{\prime}\right) 2$ fragments of goat anti-mouse immunoglobulin G (Life Technologies) were used as the secondary antibodies. Immunoflurescence was visualized using a fluorescent microscope (IX-71; Olympus).

\section{hPSC differentiation}

For spontaneous differentiation, cell-microcarrier aggregates were allowed to form embryoid bodies in differentiation media according to Chen et al. ${ }^{19}$ RNA from the differentiated cells was extracted and analyzed for pluripotent (Oct4 and Nanog), mesoderm (Nkx2.5 and Hand1), endoderm (AFP and GATA6), and ectoderm (Nestin and Pax6) marker expression. Detailed protocol and list of primers can be found in previous studies. ${ }^{19,21}$ Immunostaining of the embryoid bodies with $\alpha$-smooth muscle actin (SMA, mesoderm), $\beta$-III Tubulin (ectoderm), and alpha-fetoprotein (AFP, endoderm) antibodies was described earlier by Chan et al. ${ }^{29}$

For teratoma formation, hPSC-microcarrier cultures were mechanically dissociated by pipetting and seeded on Matrigel-coated tissue culture plates in either STEMPRO ${ }^{\circledR}$ hESC SFM or mTeSR ${ }^{\mathrm{TM}} 1$ depending on hPSC lines. After 7 days, 4-5 million cells were harvested mechanically using STEMPRO $^{\circledR}$ EZPassage ${ }^{\mathrm{TM}}$ Tool (Life Technologies) and injected into SCID mice as described in Choo et al. ${ }^{30}$ The dissected tumor was embedded in paraffin, sectioned, and stained with hematoxylin-eosin (H\&E) for histological analysis.

Directed differentiation of HES-3 on microcarriers to NPCs was carried out according to Bardy et al. ${ }^{21}$ Briefly, $10^{7} \mathrm{HES}-3$ cells expanded in spinner stirred cultures on ROCK inhibitor-treated noncoated microcarriers or Matrigel-coated microcarriers were transferred to another 100-mL spinner flask containing additional $4 \mathrm{mg} / \mathrm{mL}$ of DE-53 microcarriers and $50 \mathrm{~mL}$ of the $\mathrm{KO}$ medium (without addition of ROCK inhibitor or Blebbistatin). The cultures were differentiated for 20 days in stirring conditions $(25 \mathrm{rpm})$, During this period, Noggin treatment and medium exchanges were done as described by Bardy et al. ${ }^{21}$ Determination of PSA-NCAM expression was done by flow cytometry according to Bardy et al. ${ }^{21}$

\section{Western blot analysis}

Protein extraction from 2D and microcarrier-hPSC cultures was done using a cell lysis buffer (Cell Signaling Technology Cat. no. 9803S) supplemented with $1 \mathrm{mM}$ phenylmethanesulfonylfluoride, $1 \times$ PhosSTOP (Roche) and $1 \times$ protease inhibitor cocktail (Calbiochem Cat. no. 539134) according to the manufacturer's protocol. For microcarrier cultures, cell lysis was carried out in situ without enzymatic cell dissociation from microcarriers. Soluble proteins were separated from microcarriers and cell debris via centrifugation $(13,000 \mathrm{rpm})$ at $4^{\circ} \mathrm{C}$. Western blots were carried out as described previously ${ }^{31,32}$ using rabbit anti-MLC2 (Cell Signaling Technology), mouse anti-pMLC2 (Ser19; Cell Signaling Technology), rabbit anti-MYPT1 (Millipore) and rabbit anti-pMYPT1 (Thr 696; Millipore) antibodies. The anti-actin antibody was used as a loading control. The protein expression level was quantified by measuring the intensity of the band using ImageJ 1.43u. Lysates of HEK293 cultures were used as the positive control, which was recommended by the antibody provider (Cell Signaling Technology).

\section{Karyotype analysis}

hPSCs cultured on microcarriers were plated on Matrigelcoated $6-\mathrm{cm}$ tissue culture plate for 5 days in SFM. The harvested cultures were sent for karyotype analysis as described in Chen et al. ${ }^{19}$ Conventional cytogenetic analysis was done using the standard G-banding technique and 20 metaphases were analyzed.

\section{Statistical analysis}

Paired and unpaired Student's $t$-tests were used for statistical analysis according to experimental conditions. Error bars in the graphs represent standard errors calculated from three or more replicates. Asterisks indicate statistical significance of $p$-value $<0.05$.

\section{Results}

\section{ROCK inhibitor enables the cultivation of hPSCs on positively charged microcarriers without ECM protein coating}

The ECM protein coating on growth surface is essential for sustainable cultivation of hPSCs in 2D culture as well as suspended microcarrier culture. ${ }^{19,21,22}$ In a previous publication by Chen et al., ${ }^{19}$ it was shown that ECM (Matrigel or laminin) coatings on a variety of microcarriers, including DE53 , are essential for hESC growth. Cell concentrations of 0.8 $1.1 \times 10^{6}$ cells $/ \mathrm{mL}$ with high expression levels of pluripotent markers were obtained during the long-term cultivation on ECM-coated microcarriers. ${ }^{19}$ However, on the noncoated microcarriers, low cell growth with rapidly decreased expression of pluripotent markers was observed. ${ }^{19}$

Attempts to generate aggregate culture without microcarriers was unsuccessful; HES-3 cells seeded at a concentration of $2 \times 10^{5}$ cells / mL (with or without ROCK inhibitor at a static or agitated condition) did not show any significant cell expansion over 7 days, emphasizing the need for attachment to microcarriers for initiation of cell growth (data not shown). 
Thus, to achieve growth in cell-microcarrier aggregate cultures without addition of the ECM, we tested the possibility of propagating hESCs on noncoated microcarriers in the presence of the ROCK inhibitor. HES-3 were seeded at a cell density of $2 \times 10^{5}$ cells $/ \mathrm{mL}$ on $4 \mathrm{mg} / \mathrm{mL}$ noncoatedpositive charged DE-53 microcarriers in StemPro hESC SFM containing $0.25-10 \mu \mathrm{M}$ of the ROCK inhibitor, Y27632. Cell growth and pluripotency were monitored for five passages. Matrigel-coated and noncoated DE-53 microcarrier (without ROCK inhibitor) cultures were used as positive and negative controls. In the negative control of noncoated DE-53 microcarriers, hESC cultures without ROCK inhibitor obtained low cell growth (Fig. 1A) and viable culture was maintained for only two passages (data not shown).

In the presence of ROCK inhibitor $(2-10 \mu \mathrm{M})$, cells were able to attach to DE-53 microcarriers, and expanded for at least sevenfold, while maintaining steady cell growth of $1.4-1.8 \times 10^{6}$ cells $/ \mathrm{mL}$ and high levels of pluripotency (Oct4 $>77 \%$ and $\mathrm{mAb} 84>78 \%$ ). Cultures with ROCK inhibitor at concentrations of 5 and $10 \mu \mathrm{M}$ showed comparable expression levels of pluripotency markers as Matrigel-coated microcarrier cultures (Fig. 1B, $p$-value $=0.21$ ). Short-term treatment with ROCK inhibitor $(10 \mu \mathrm{M}, 1-2$ days after cell seeding) of HES-3 DE-53 microcarriers (noncoated) resulted in a decrease in pluripotency markers (Oct4 56-71\%, mAb84 $41-48 \%$, and Tra-1-60 61-69\% after two passages). ROCK inhibitor-treated Matrigel-coated DE-53 microcarrier cultures achieved similar levels of cell growth and expression of the pluripotent marker (Tra-1-60) as nontreated ones (Supplementary Fig. S1; Supplementary Data are available online at www.liebertpub.com/tec). Cell attachment efficiency to the microcarriers was very high $(85-93 \%$ in $15 \mathrm{~min})$ regardless of ROCK inhibitor treatment or Matrigel coating of the microcarriers (data not shown). The universality of hPSC response to ROCK inhibitor treatment in noncoated microcarrier cultures was demonstrated using other hPSC lines (H7 hESC and hiPSC [IMR90]), all three cell lines were able to grow on these coating-free microcarriers in the presence of a $10 \mu \mathrm{M}$ ROCK inhibitor (Fig. 1C).

To verify the long-term robustness of the ROCK inhibitorbased microcarrier culture, HES-3, H7, and hiPS (IMR90) cells were propagated for $12-15$ passages. All cultures achieved average cell concentrations of $1.29 \times 10^{6}$ cells $/ \mathrm{mL}$ and high expression levels of pluripotent markers, which were comparable to Matrigel-coated microcarrier cultures ( $p$ value $>0.05$ ) (Fig. 2). hPSC microcarrier culture treated with ROCK inhibitor exhibited spherical shape cell-microcarrier aggregates, whereas Matrigel-coated microcarrier culture has more irregular structures (Fig. 3A, B). The cell-microcarrier aggregates were composed of 1-10 hESC layers separated by microcarriers (H\&E staining, data not shown). This structure suggests that the formation of the aggregates was initiated by cell attachment on microcarriers (cell attachment of $95 \pm 1 \%$ was achieved in $15 \mathrm{~min}$,) followed by joining of several small aggregates to form larger ones. After 7 days, cell-microcarrier aggregates had reached an average diameter of $520 \pm 240 \mu \mathrm{m}$.

The different morphology of the aggregates can be attributed to the inhibition of ROCK, which is known to be involved in regulating the shape and movement of cells by acting on stress fibers. ${ }^{33}$ Immunostaining of pluripotency markers of the ROCK inhibitor-treated noncoated HES-3
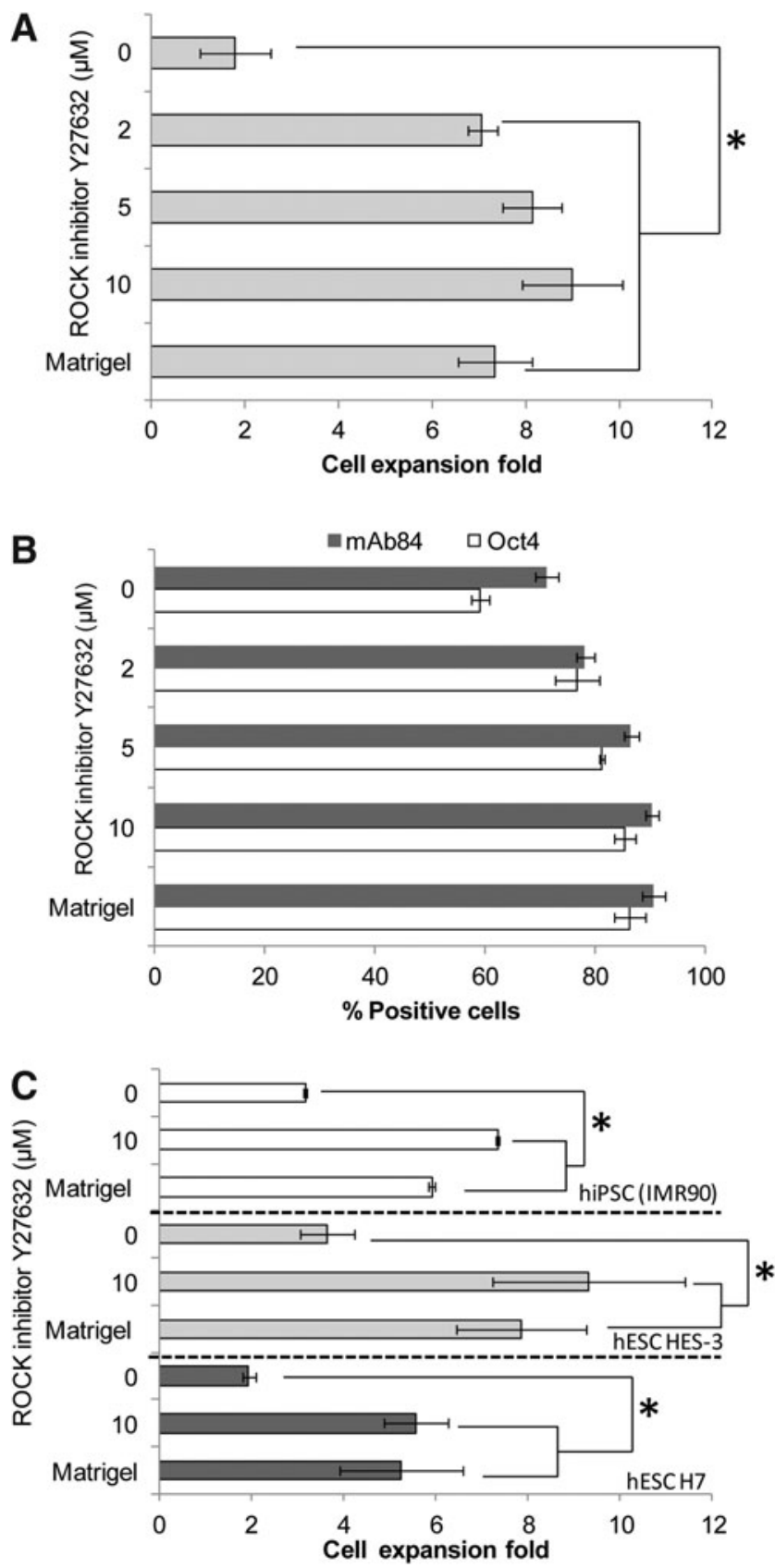

FIG. 1. ROCK inhibitor supports human pluripotent stem cell (hPSC) growth on noncoated microcarriers. Cells were seeded at a concentration of $2.0 \times 10^{5}$ cells $/ \mathrm{mL}$ on noncoated DE-53 microcarriers and cultured for five consecutive passages in a static condition. Matrigel-coated microcarrier cultures were used as the positive control without ROCK inhibitor treatment. (A) Average HES-3 cell expansion fold and (B) pluripotent marker expression level obtained after 7 days of growth in cultures treated with various concentrations of ROCK inhibitor, Y27632. (C) ROCK inhibitor also support cell growth of $\mathrm{H7}$ and human induced pluripotent stem cell (hiPSC, IMR90) on noncoated microcarriers. hPSCs on noncoated microcarriers without ROCK inhibitor maintained viable cell culture for two passages only. Error bar indicates standard errors. ${ }^{*} p$-value $<0.05$. ROCK, Rhoassociated kinase. 

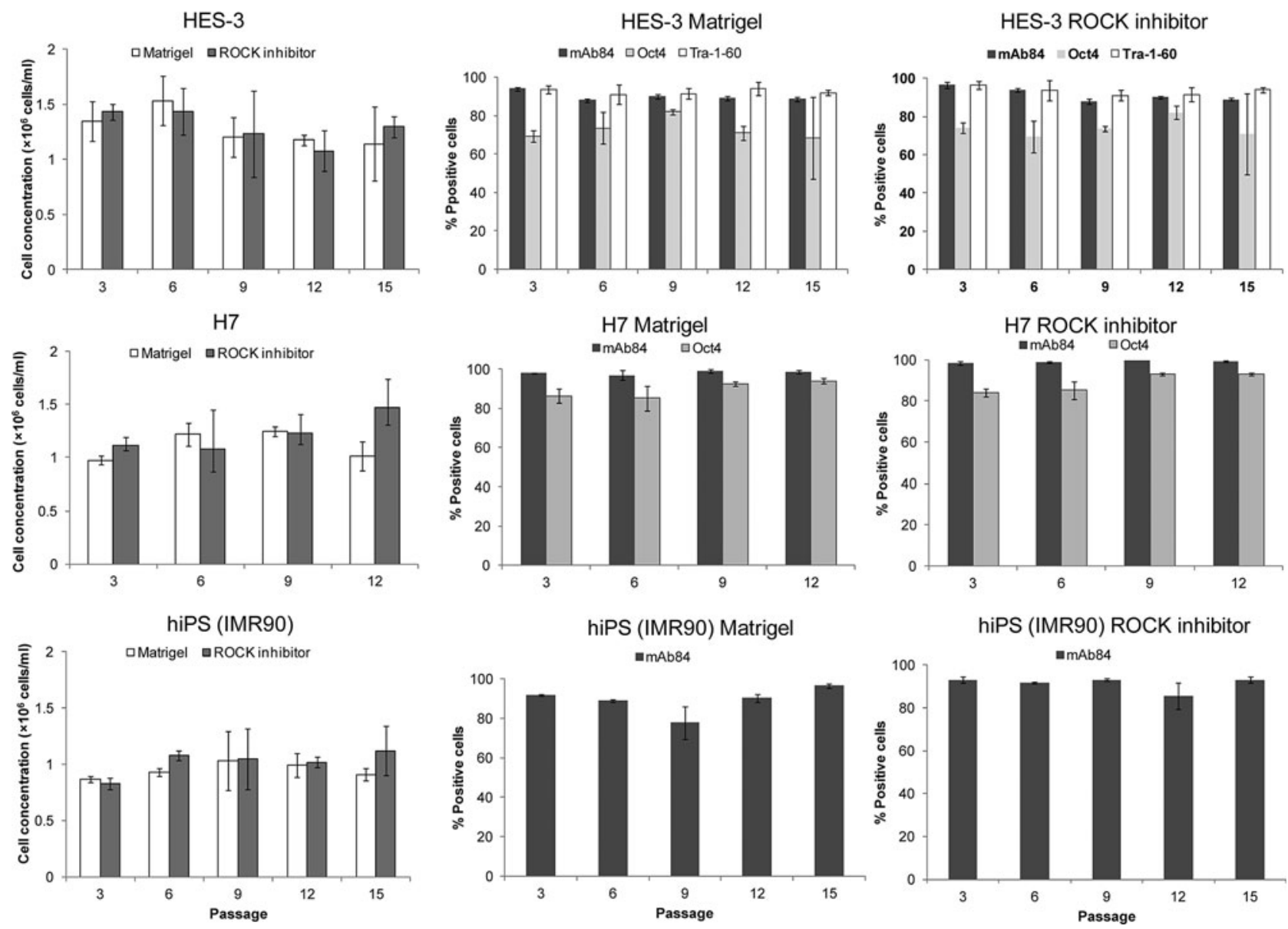

FIG. 2. Long-term cultivation of three hPSC lines on ROCK inhibitor-treated noncoated microcarrier cultures as compared to Matrigel-coated ones. In each passage, $2 \times 10^{5}$ cells $/ \mathrm{mL}$ were seeded on $4 \mathrm{mg} / \mathrm{mL}$ fresh microcarriers for 7 days. Cell concentrations and pluripotent markers were measured on day 7. Error bars indicate standard errors.

microcarrier-cell aggregates show positive expression of the pluripotent marker Oct4 (Fig. 3C). The karyotype of HES-3 cells treated with the ROCK inhibitor remained normal for at least 15 passages (Supplementary Fig S2). Similar results were obtained using hESC (H7) and hiPSC (IMR90) lines demonstrating the universality of the system (Supplementary Fig. S2).

\section{Inhibition of myosin II is associated with hPSC growth on noncoated microcarriers}

ROCK affects several downstream targets of Rho and is mainly involved in regulating the shape and motility of cells by acting on the actin cytoskeleton regulation. ${ }^{33}$ The formation of stress fibers is generated by phosphorylation of myosin light chain 2 (MLC2) that is induced by ROCK. Due to this phosphorylation, the actin binding of myosin II is enhanced and initiates the contraction of the cytoskeleton actin fibers. ${ }^{33}$ To verify that cell growth on noncoated microcarriers is related to inhibition of myosin, we tested Blebbistatin, which directly inhibits myosin II heavy chain, ${ }^{13,34,35}$ for supporting hPSC growth on noncoated microcarriers. Phosphorylation levels of MLC2 and myosin phosphatase (MYPT1, which is located upstream to MLC2) were measured in ROCK inhibitor- and Blebbistatin-treated microcarrier cultures and compared to untreated cultures (Matrigel coated).
HES-3 cells were seeded on noncoated microcarriers in STEMPRO ${ }^{\circledR}$ hESC SFM in the presence of $10 \mu \mathrm{M}$ of Blebbistatin in parallel to control cultures that contain $10 \mu \mathrm{M}$ of ROCK inhibitor. Cell growth was maintained in both systems (12 passages) achieving an average cell concentration of $1.06 \pm$ $0.10 \times 10^{6}$ and $1.32 \pm 0.11 \times 10^{6}$ cells $/ \mathrm{mL}$ for Blebbistatin- and ROCK inhibitor-treated cultures, respectively (Fig. 4A). Expression levels of pluripotent markers, Oct4, mAb84, and Tra$1-60$, were similar in both microcarrier cultures ( $p$-value $>0.05)$ (Fig. 4A).

We next analyzed the effect of ROCK inhibitor and Blebbistatin on the phosphorylation of MYPT1 and MLC2 in microcarrier cultures. Western blot analysis show that hESCs (HES-3 and H7) propagated on noncoated microcarriers in the presence of ROCK inhibitor or Blebbistatin (Fig. 4) exhibited lower levels of phosphorylated MYPT1 (pMYPT1) and MLC2 (pMLC2) when compared to Matrigel-coated microcarrier cultures. Thus, it appears that the reduction in actin-myosin contractility via ROCK inhibitor or Blebbistatin treatments lead to the survival and active growth of hPSCs on noncoated microcarriers.

\section{Expansion of hPSCs in ROCK inhibitor-treated stirred spinner flask microcarrier culture}

To demonstrate the scalability of the ROCK inhibitortreated noncoated microcarrier culturing system, we 
A

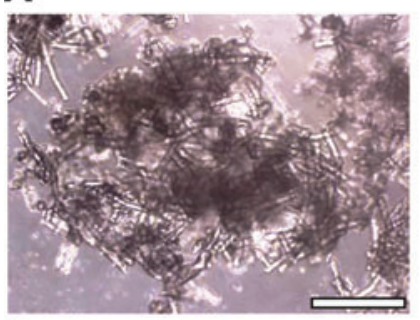

C

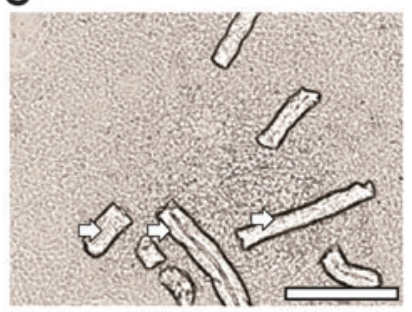

Phase contrast

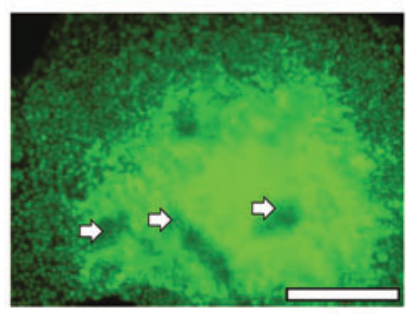

Oct4

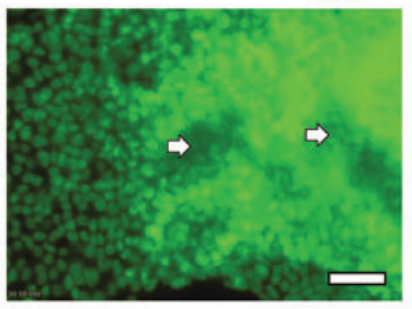

Oct4
B
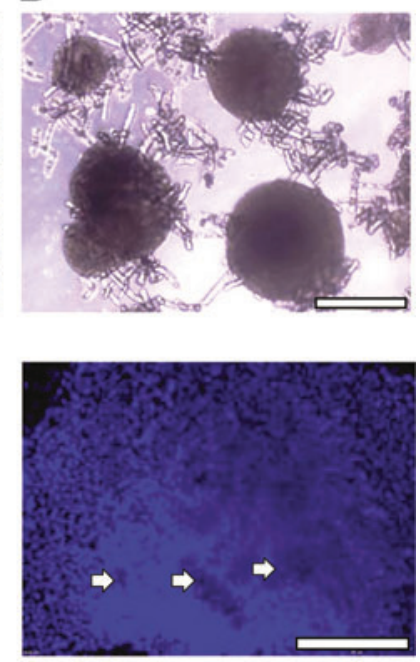

DAPI

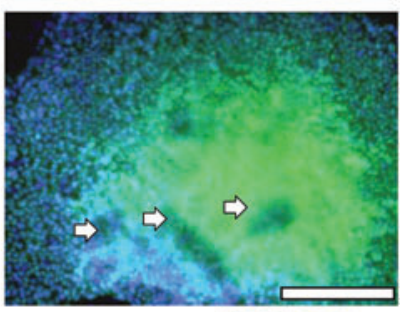

DAPI Oct4

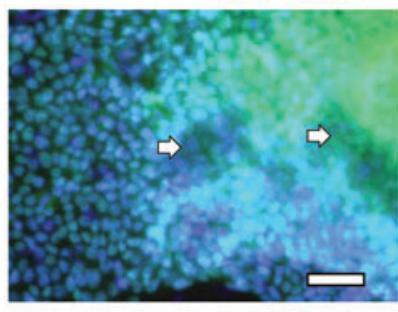

DAPI Oct4

FIG. 3. Immunostaining and morphology of ROCK inhibitor-treated cell-microcarrier aggregates obtained from static cultures (7 days). Phase-contrast image of HES-3 cells cultured on (A) Matrigel-coated and (B) noncoated ROCK inhibitor-treated microcarrier cultures. (C) Phase-contrast image and immunostaining of HES-3 cell-microcarrier aggregates plated on a Matrigel-coated plate show positive expression of Oct4. White arrows indicate microcarriers. Nuclei were stained blue with 4',6-diamidino-2-phenylindole (DAPI). Scale bars indicate $200 \mu \mathrm{m}$.

propagated HES-3 and H7 cells on Matrigel-coated and noncoated DE-53 microcarrier spinner cultures and compared their cell growth and pluripotency. Matrigel-coated and ROCK inhibitor-treated microcarrier cultures of both hESC lines exhibited similar growth profiles (Fig. 5A). After 1 day lag phase, HES-3 cells grow exponentially showing similar doubling times of 27.0 and $27.7 \mathrm{~h}$ and maximal viable cell density of $2.3 \times 10^{6}$ and $2.5 \times 10^{6}$ cells $/ \mathrm{mL}$ ( $p$-value $=0.075>0.05)$ for ROCK inhibitor-treated and Matrigelcoated microcarrier cultures, respectively. H7 cells exhibited also similar doubling time and maximal cell density (Matrigel-coated microcarrier: $32.5 \mathrm{~h}$ and $3.33 \times 10^{6}$ cells $/ \mathrm{mL}$;

ROCK inhibitor-treated microcarrier culture: $32.2 \mathrm{~h}$ and $3.36 \times 10^{6}$ cells $/ \mathrm{mL}$ ). ROCK inhibitor-treated hPSC microcarrier cultures (HES-3 and H7) appeared to have higher expression levels of pluripotent markers (although not significant) than Matrigel-coated nontreated ones (Oct4 $67-94 \%$ vs. $42-80 \%$, $p$-value $=0.34)$, mAb84 (91-98\% vs. $63-$ $80 \%, p$-value $=0.04)$, and Tra-1-60 $(91-98 \%$ vs. $59-88 \%$, $p$-value $=0.12)$. Moreover, a minor peak adjacent to the negative control appears only in the flow cytometry histograms of the Matrigel-coated microcarrier culture indicating the presence of a small population of differentiating cells in this culture (Fig. 5B). These results can imply that ROCK inhibitor-treated hPSCs undergo structural cytoskeleton changes, which may have reduced the propensity of the cells to differentiate spontaneously, induced by fluidic shear stress. $^{36}$ Further work is needed to substantiate this assumption. Similar to static microcarrier cultures, ROCK inhibitor-treated spinner flask culture exhibited more spherical cell-microcarrier aggregates than those in Matrigel-coated spinner flask culture. In both cultures, the cylindrical DE-53 microcarriers were embedded in the aggregates between the cell layers (Fig. 5C, D). Cells harvested from these cultures exhibited high levels of viability (>90\%) and H\&E staining of the sectioned cell-microcarrier aggregates showed intact cells at the periphery and center of the aggregates without visible necrosis (Data not shown).

Embryoid body culture and teratoma generation in SCID mice were done to evaluate the differentiation capability of the ROCK inhibitor-treated microcarrier cultures. Increased transcription levels of representative genes from three germ lineages and a decrease in pluripotent markers (Oct4 and Nanog) were demonstrated in embryoid body (cellmicrocarrier aggregates) cultures (Fig. 6A). Immunostaining of differentiated embryoid bodies plated on gelatin-coated tissue culture plates also showed positive expression of representative endoderm (AFP), ectoderm ( $\beta$-III Tubulin), and mesoderm (SMA) proteins (Fig. 6B). Teratoma generated in SCID mice contained tissues from the three germ lineages, namely, rosettes of neural epithelium, gut-like epithelium, and cartilage (Fig. 6C).

Noncoated, ROCK inhibitor-treated HES-3 microcarrier spinner flask cultures were differentiated to NPCs using the protocol described by Bardy et al. ${ }^{21}$ After 16-20 days of differentiation in stirred spinner culture, highest levels of PSA-NCAM-positive NPCs were obtained $(90.9 \pm 1.1 \%$ PSANCAM-positive, viable cell density of $9.1 \pm 1.2 \times 10^{6}$ cells / $\mathrm{mL}$, and yield of $412 \pm 77 \mathrm{NPC}$ ser seeded HES-3). These yields are comparable to the highest ones obtained from a parallel Matrigel-coated microcarrier culture at day 16 $(94.5 \pm 2.8 \%$ PSA-NCAM-positive cells, viable cell density of $9.3 \pm 0.6 \times 10^{6}$ cells $/ \mathrm{mL}$, and yield of $368 \pm 43$ NPCs per seeded HES-3) (Supplementary Fig. S3). These cells also expressed typical NPC markers (PAX6 and Nestin) when replated on Matrigel-coated plates (Fig. 6D).

\section{Discussion}

Microcarrier technology has proven to be a scalable culturing platform for hPSC expansion and subsequent differentiation to definitive endoderm, neural progenitors, and cardiomyocytes. ${ }^{17-19,21,23,37,38}$ Similar to 2D culture, for hPSC cultivation, Matrigel coating has been shown to be essential 
A

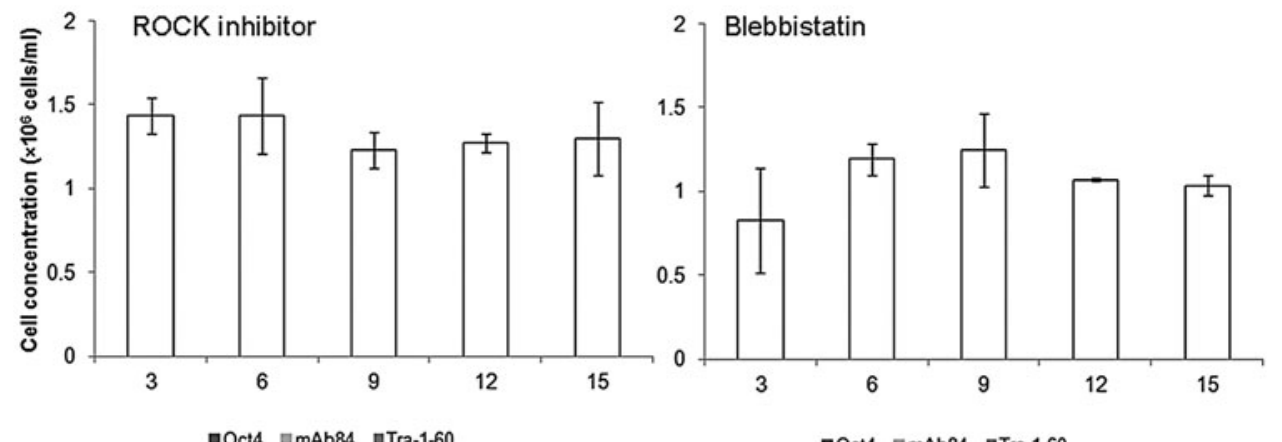

FIG. 4. ROCK inhibitor and Blebbistatin treatment decrease phosphorylation of MYPT1 and MLC2 and en-

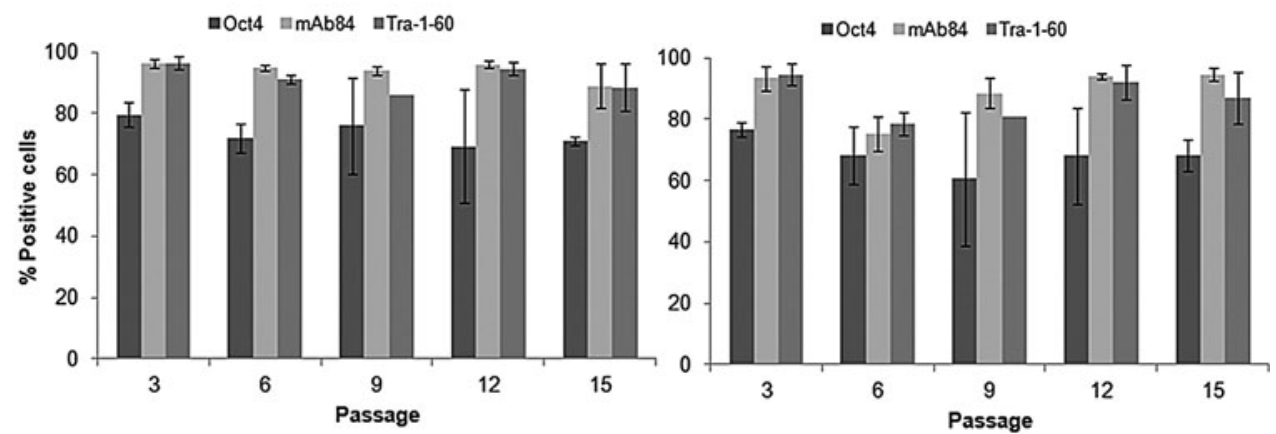
able human embryonic stem cell (hESC) growth on noncoated microcarriers. (A) Blebbistatin- and ROCK inhibitor-treated microcarrier cultures show similar longterm growth and expression of pluripotent markers. (B) Western blots and image quantification of MYPT1 and MLC2 phosphorylation of two hPSC lines, HES-3 and $\mathrm{H} 7$, in Matrigel-coated microcarrier culture versus noncoated ROCK inhibitor-

B HES-3
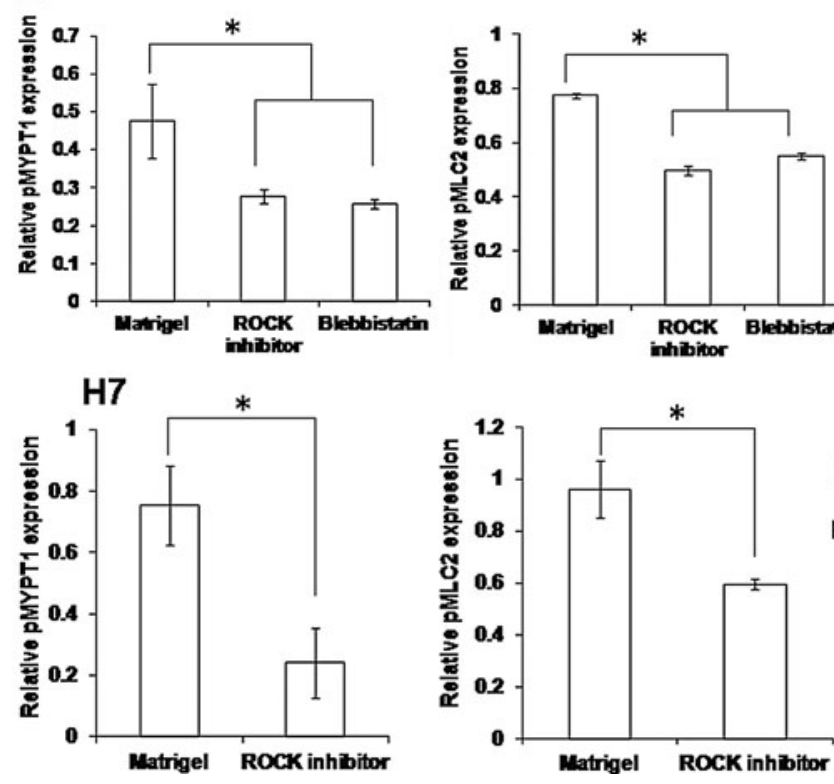
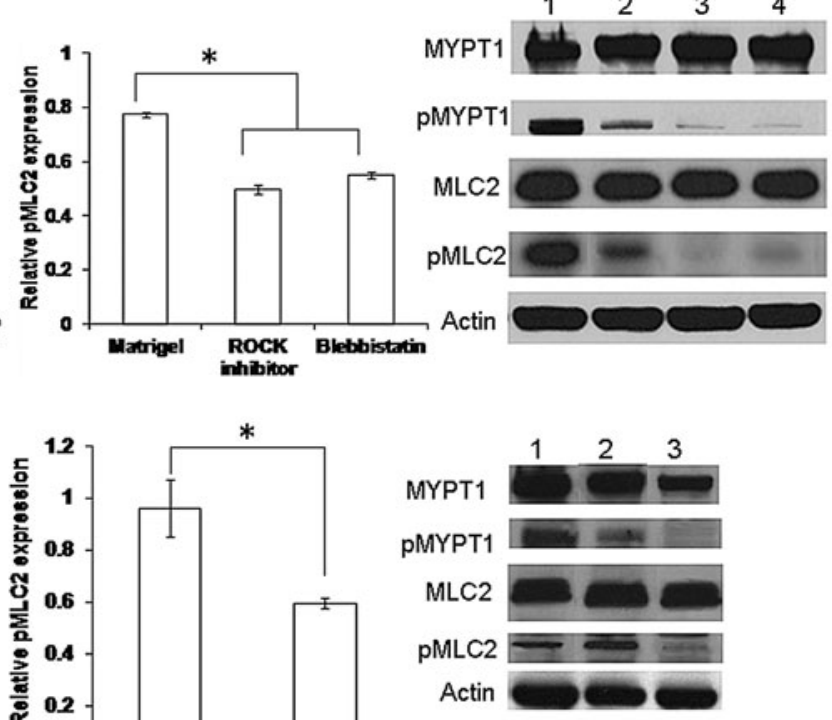

and Blebbistatin-treated ones. Column 1: positive control (HEK293 cell lysate), Column 2: Matrigel-coated microcarrier culture, Column 3: ROCK inhibitor-treated noncoated microcarrier culture, Column 4: Blebbistatintreated noncoated microcarrier culture. Error bars indicated standard deviations obtained from three consecutive passages. ${ }^{*} p$-value $<0.05$. for growth on microcarriers. ${ }^{17,19}$ The complexity of Matrigel composition and its animal origin may pose a challenge in applying the hPSC microcarrier expansion platform for clinical applications. Studies have reported alternatively defined matrices like laminin (mouse and human), 6,8,22,39,40 human vitronectin (plasma purified or recombinant), $9,10,22$ and fibronectin ${ }^{40}$ can replace Matrigel coating for supporting hPSC cultivation. However, these ECM proteins may not be suitable for large-scale production as they either contain components of animal origin or are expensive to produce and purify.

In this study, we have shown that hPSCs (hESCs and hiPSCs) can be cultured on noncoated microcarrier cultures for at least 12 passages simply by adding ROCK inhibitor (Y27632) or Blebbistatin. We also demonstrate that cell growth, expression levels of pluripotency markers, and scalability of ROCK inhibitor- and Blebbistatin-treated microcarrier cultures are comparable to those cultured on Matrigel-coated microcarriers. Both in vitro and in vivo spontaneous differentiation procedures were able to generate cells of the three germ layers. Moreover, efficient differentiation to NPCs was demonstrated in stirred cultures. We have found that long-term exposure of hPSCs to ROCK inhibitor has no adverse effect on cell growth, pluripotency, karyotype stability, and directed differentiation to neural progenitors, which is consistent with similar findings in other 
A

FIG. 5. Comparison of cell growth, pluripotent marker expression, and morphology of hPSCs cultured on Matrigel-coated and noncoated ROCK inhibitor-treated DE53 microcarrier spinner flask cultures. (A) Cell growth kinetics and (B) expression pluripotent markers after 7 days of growth. Phasecontrast images of cellmicrocarrier aggregates obtained from (C) Matrigelcoated and (D) ROCK inhibitor-treated microcarrier spinner flask cultures. Scale bars indicate $200 \mu \mathrm{m}$.

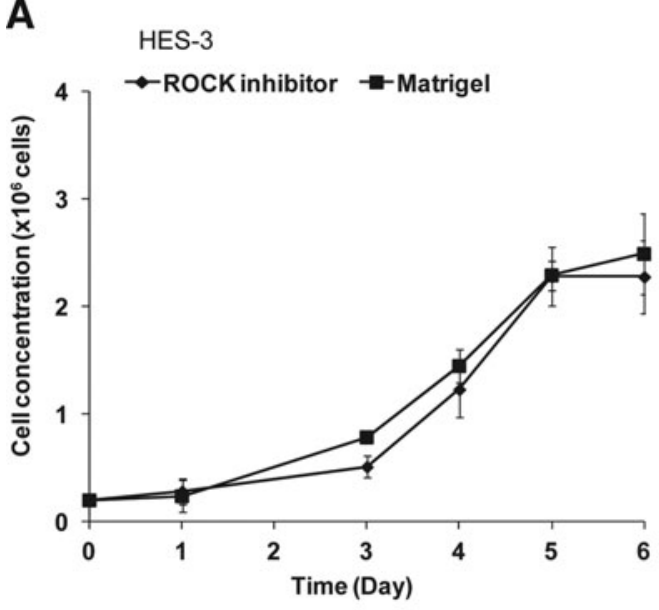

B
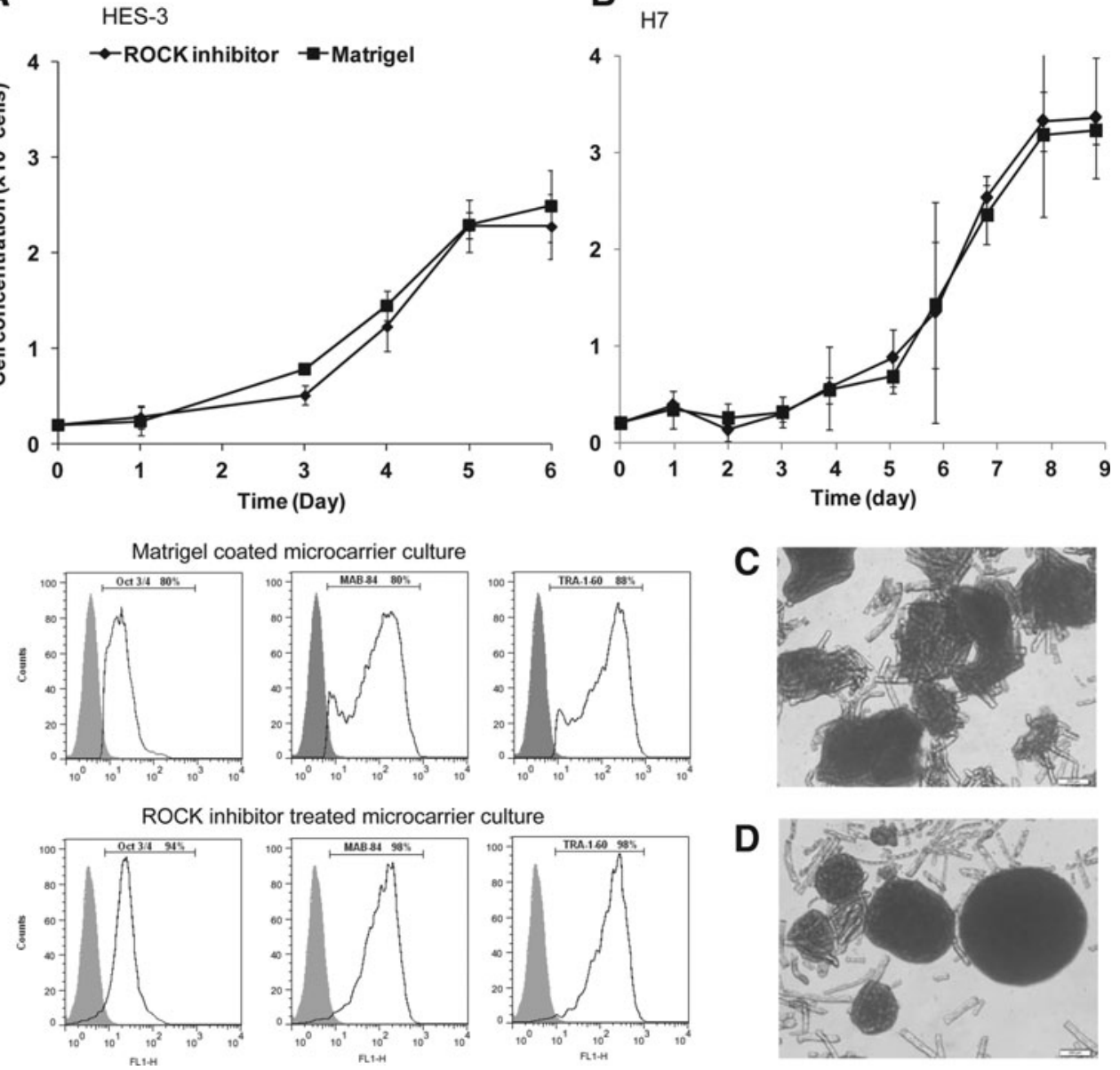

D

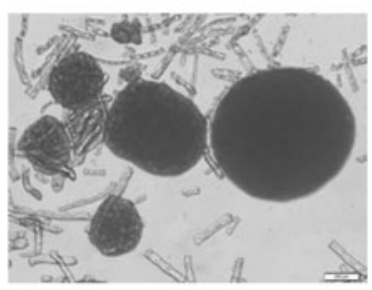

studies. ${ }^{14,41-44}$ The use of ROCK inhibitor eliminates the need of ECM coatings on microcarriers for hPSC cultivation. This is an important step toward the development of a defined serum-free hPSC expansion platform for both research and clinical applications.

ROCK inhibitor, Y27632, has been used widely in a variety of applications that involved hPSC dissociation. ${ }^{14,32,35}$ It has been shown that addition of ROCK inhibitor to dissociated hPSCs can improve the cell survival rate and plating efficiency. ${ }^{14,32,35}$ Other studies also showed improved recovery of cryopreserved hPSCs or its differentiated progenies when ROCK inhibitor was added. ${ }^{45}$ Several groups have tried to address the underlining mechanism of ROCK inhibitor in preventing cell dissociation-induced apoptosis. It has been shown that ROCK inhibitor does not prevent the apoptosis directly. Prevention of apoptosis was attributed to ROCKdependent myosin II hyperactivation. ${ }^{13,32,35,46}$ We were not successful in achieving stable hESC aggregate cultures with ROCK inhibitor alone. However, several groups have utilized ROCK inhibitor to culture hPSCs as cell aggregates without microcarriers. ${ }^{38,47-51}$ These aggregate cultures have been reported to reach comparable cell concentrations of 1.0$1.9 \times 10^{6}$ cells $/ \mathrm{mL}$ (2.5-17.7-fold expansion). ${ }^{48,49,51}$ Even though these cell aggregate cultures have advantages in cost reduction and simpler downstream processing as compared to microcarrier cultures, they have several limitations that still need to be addressed. In cell aggregate culture, where the whole aggregates are comprised of cells only, the lack of proper monitoring can lead to excessive multilayered cells and result in limited nutrient diffusion. Whereas in microcarrier culture, such excessive multilayered cells would not occur when adequate microcarriers are provided in the culture. As shown in Figures 3 and 5, cell-microcarrier aggregates had layer thickness of up to 10 cells with microcarriers embedded in the microcarrier-cell aggregates. Hence, nutrient deficiency due to diffusion limitation is significantly lower in microcarrier culture than aggregate culture. In previous publications, we have demonstrated that hESC microcarrier culture achieve higher cell yields than 2D cultures (1.7-1.9-fold) and over 90\% viability indicating no nutrient diffusion limitation. ${ }^{17,21}$ Moreover, there is no need for manual manipulation of the culture during the 7 days of cell growth and the culture can be passaged efficiently with or without enzymatic treatment at wide range of seeding densities. $^{27}$ In aggregate cultures, frequent intervention and stringent controls are needed, cells are seeded at controlled low density (cell aggregate), and manual dissociation is needed to control the aggregate size. ${ }^{49-52}$ Moreover, during culture passaging, significant cell death occurs due to enzyme disaggregation treatment. ${ }^{49-52}$

hPSCs have net negative surface charges and attach efficiently to positive charged cellulose microcarriers. ${ }^{19}$ This cell attachment is adequate to support hPSC spreading and growth for the short term (two passages) on noncoated 

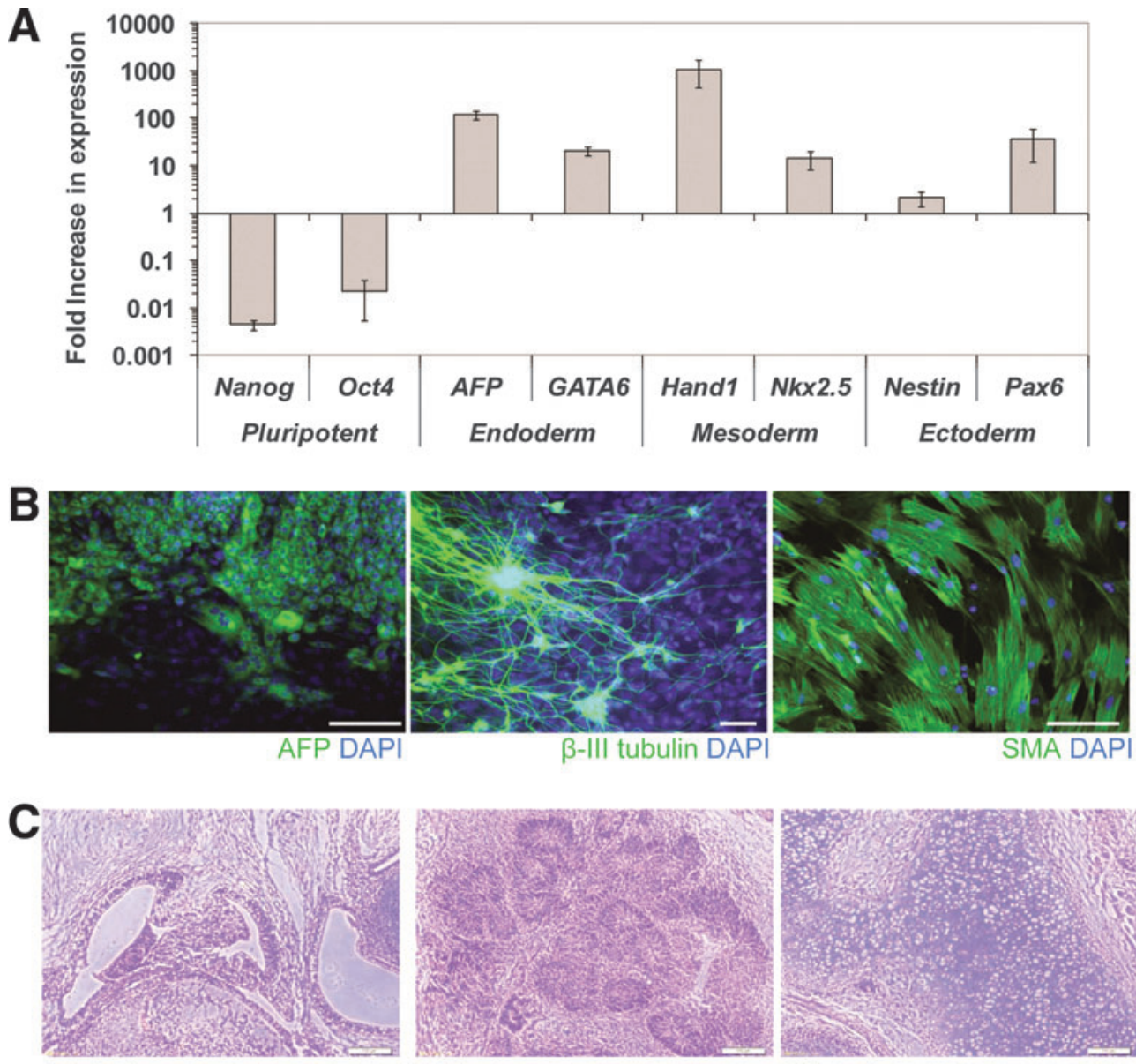

Endoderm
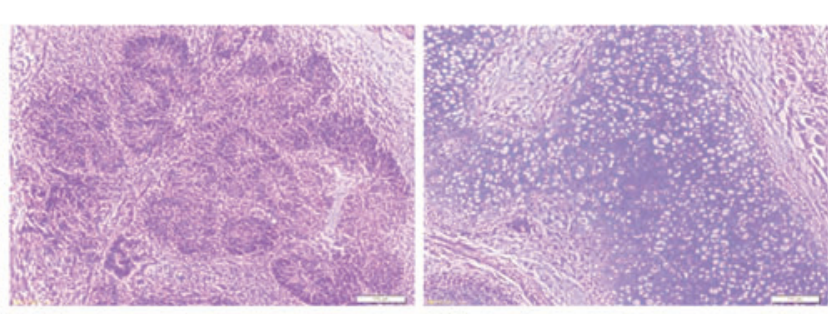

Ectoderm

Mesoderm
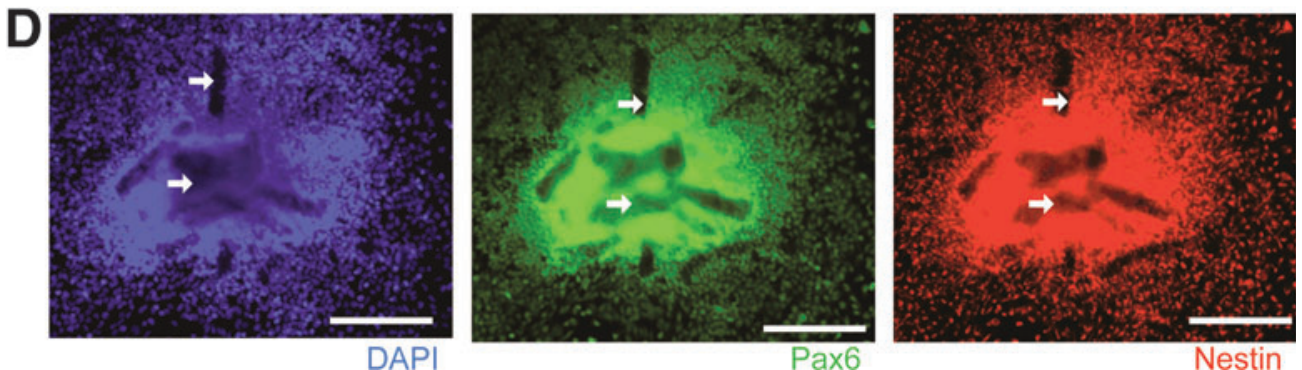

FIG. 6. ROCK inhibitor-treated HES-3 microcarrier cultures have differentiation capabilities. (A) Quantitative real-timepolymerase chain reaction analysis of spontaneous differentiated embryoid bodies (cell-microcarrier aggregates) showed elevated expression of genes from three germ layers. (B) Immunostaining of replated embryoid bodies showing the formation of cells expressing alpha-fetoprotein (AFP, endoderm), $\beta$-III tubulin (ectoderm), and $\alpha$-smooth muscle actin (SMA, mesoderm). (C) Hematoxylin-eosin staining of teratoma generated in SCID mouse showing the three germ layers, gut epithelia (endoderm), neural rosettes (ectoderm), and cartilage (mesoderm). (D) Immunohistochemistry of plated neurospheres generated from ROCK inhibitor-treated microcarrier cultures stained positive for neural progenitor markers, Pax6 and Nestin. White arrows indicate microcarriers. Scale bars indicate $200 \mu \mathrm{m}$.

microcarriers, but not for long-term growth and maintenance of pluripotency. ${ }^{17,19,21}$ In this study, we show that hPSCs can grow on these noncoated microcarriers in the presence of ROCK inhibitor and Blebbistatin. These cultures exhibit significant lower expression levels of PMYPT1 and pMLC2 proteins (as compared to Matrigel-coated microcarrier cultures), indicating a reduction in myosin II-mediated cell contractility. The involvement of the ROCK-Myosin II signaling pathway in supporting hPSC growth on noncoated microcarriers was validated by using myosin II inhibitor (Blebbistatin). We postulate that these inhibitors mediated cytoskeletal reorganization, in which, myosin II is the key regulator that enables hPSCs to maintain growth and pluripotency on noncoated microcarriers.

ROCK inhibitor-mediated cytoskeletal reorganization affects spatial organization (i.e., the microenvironment) of hPSCs on microcarriers via altering cell-cell and cell-ECM interactions similar to those observed in 2D hPSC cultures. 
This microenvironment has been widely known to determine the fate of hPSCs. ${ }^{53,54}$ The increase in cell-cell interaction via E-cadherin modulation has been reported to improve hPSC survival. ${ }^{35}$ Addition of ROCK inhibitor to hPSC colonies was shown to increase Oct4 expression, which was attributed presumably to the reduction in actomyosin tension within hPSC colonies. ${ }^{54,55}$ Pakzad et al. ${ }^{44}$ showed that the addition of ROCK inhibitor to hPSC culture exhibited upregulation of integrins $(\alpha \mathrm{V}, \alpha 6$, and $\beta 1)$ associated with pluripotency of hPSCs. ${ }^{44,56}$ The changes in integrin organization led to enhanced cell adhesion to the ECM and disposition of ECM proteins that support self-renewal of hPSCs. ${ }^{4,56}$ In our study, a high level of cell attachment is achieved by the positively charged surface of the DE-53 microcarriers, in which, 85-93\% cell attachment was observed in 15 min (data not shown). This suggested that in the case of positively charged microcarrier cultures (DE-53), ROCK inhibitor treatment-mediated integrin expression might not play a significant role in hPSC attachment efficiency to the DE-53 microcarriers. There are many studies and reviews addressing the issue of the effect of ROCK inhibitor treatment on cytoskeletal reorganization, hPSC growth, pluripotency, and differentiation propensity. ${ }^{32,42,57-63}$ However, up until now, the direct correlation between ROCK inhibitor-mediated cytoskeletal reorganization and the mode of hPSC growth has not been elucidated convincingly. More extensive basic research is needed to clarify these issues.

Agitation stress has been shown to influence differentiation commitment in hPSCs. Leung et al. showed that hESCs (HES-3) propagated on Matrigel-coated DE-53 microcarriers in agitated spinner flasks exhibited lower pluripotency marker expressions when compared to static microcarrier cultures. ${ }^{36}$ A later study by Chen et al. showed the impact of ECM microcarrier coating on pluripotency of hPSCs in agitated spinner flasks. hESCs propagated on laminin-coated microcarrier spinner flasks were more prone to differentiation than Matrige- coated ones. ${ }^{19}$ Similar observations of shear-induced differentiation were also found with mesenchymal stem cells (MSCs). Datta et al. demonstrated synergistic effects of fluidic shear and ECM coating on scaffolds on osteogenic differentiation of rat MSCs. ${ }^{64}$ Arnsdorf et al. also found that exposure of murine MSCs to oscillatory flow induced increased cytoskeletal tension and expressions of differentiation markers. ${ }^{31}$ Both the cytoskeletal changes and differentiation could be curtailed by addition of ROCK inhibitor or Blebbistatin. ${ }^{65}$ Teramura et al. showed similar effects using hiPSC, ROCK inhibitor treatment prevented downregulation of pluripotent markers caused by cyclic tensile forces. ${ }^{66}$ In this study, we have shown that ROCK inhibitor treatment reduces agitation shear-induced spontaneous differentiation observed previously in ECM-coated microcarrier spinner flask cultures. ${ }^{19}$ As shown in Figure 5, both hESC lines (HES-3 and H7) treated with ROCK inhibitor displayed higher expression levels of pluripotency markers when compared to untreated hESCs on Matrigelcoated microcarriers. Based on this observation, it seems that cytoskeletal reorganization resulting from ROCK inhibitor treatment allows hPSC microcarrier cultures to resist fluidic shear-induced spontaneous differentiation.

In conclusion, we have demonstrated culturing of hPSCs on noncoated microcarriers in a defined serum-free medium. The elimination of ECM coatings from the microcarrier sur- face will facilitate the translation of the hPSC microcarrier expansion platform into clinical applications. As discussed above, we have shown that probably due to ROCK inhibitormediated cytoskeleton changes, hPSCs can be propagated on noncoated microcarriers. However, further study is needed to address the complexity of mechanotransduction pathways and their impact on hPSC microcarrier culture.

\section{Acknowledgments}

The authors would like to acknowledge Dr. Andre Choo (Bioprocessing Technology Institute, Singapore) for the teratoma assay and Dr. Kah Yong Tan (Bioprocessing Technology Institute, Singapore) for his critical review of the manuscript. This work was generously supported by the Agency for Science, Technology and Research (A*STAR), Singapore.

\section{Disclosure Statement}

No competing financial interests exist.

\section{References}

1. Thomson, J.A., Itskovitz-Eldor, J., Shapiro, S.S., Waknitz, M.A., Swiergiel, J.J., Marshall, V.S., et al. Embryonic stem cell lines derived from human blastocysts. Science 282, 1145, 1998.

2. Reubinoff, B.E., Pera, M.F., Fong, C.-Y., Trounson, A., and Bongso, A. Embryonic stem cell lines from human blastocysts: somatic differentiation in vitro. Nat Biotechnol 18, 399, 2000.

3. Lerou, P.H., and Daley, G.Q. Therapeutic potential of embryonic stem cells. Blood Rev 19, 321, 2005.

4. Xu, C., Jiang, J., Sottile, V., McWhir, J., Lebkowski, J., and Carpenter, M.K. Immortalized fibroblast-like cells derived from human embryonic stem cells support undifferentiated cell growth. Stem Cells 22, 972, 2004.

5. Ding, V., Choo, A.B., and Oh, S.K. Deciphering the importance of three key media components in human embryonic stem cell cultures. Biotechnol Lett 28, 491, 2006.

6. Xu, C., Inokuma, M.S., Denham, J., Golds, K., Kundu, P., Gold, J.D., et al. Feeder-free growth of undifferentiated human embryonic stem cells. Nat Biotechnol 19, 971, 2001.

7. Miyazaki, T., Futaki, S., Hasegawa, K., Kawasaki, M., Sanzen, N., Hayashi, M., et al. Recombinant human laminin isoforms can support the undifferentiated growth of human embryonic stem cells. Biochem Biophys Res Commun 375, 27, 2008.

8. Rodin, S., Domogatskaya, A., Ström, S., Hansson, E.M., Chien, K.R., Inzunza, J., et al. Long-term self-renewal of human pluripotent stem cells on human recombinant laminin-511. Nat Biotechnol 28, 611, 2010.

9. Yap, L.Y., Li, J., Phang, I.Y., Ong, L.T., Ow, J.Z., Goh, J.C.H., Nurcombe, V., et al. Defining a threshold surface density of vitronectin for the stable expansion of human embryonic stem cells. Tissue Eng Part C Method 17, 193, 2010.

10. Braam, S.R., Zeinstra, L., Litjens, S., Oostwaard, D.W.-v., van den Brink, S., van Laake, L., et al. Recombinant vitronectin is a functionally defined substrate that supports human embryonic stem cell self-renewal via alphavbeta5 integrin. Stem Cells 26, 2257, 2008.

11. Melkoumian, Z., Weber, J.L., Weber, D.M., Fadeev, A.G., Zhou, Y., Dolley-Sonneville, P., et al. Synthetic peptide-acrylate surfaces for long-term self-renewal and cardiomyocyte differentiation of human embryonic stem cells. Nat Biotechnol 28, 606, 2010. 
12. Harb, N., Archer, T.K., and Sato, N. The Rho-Rock-Myosin signaling axis determines cell-cell integrity of self-renewing pluripotent stem cells. PLoS One 3, e3001, 2008.

13. Walker, A., Su, H., Conti, M.A., Harb, N., Adelstein, R.S., and Sato, N. Non-muscle myosin II regulates survival threshold of pluripotent stem cells. Nat Commun 1, 71, 2010.

14. Watanabe, K., Ueno, M., Kamiya, D., Nishiyama, A., Matsumura, M., Wataya, T., et al. A ROCK inhibitor permits survival of dissociated human embryonic stem cells. Nat Biotechnol 25, 681, 2007.

15. Mummery, C.L. Cardiology: solace for the broken-hearted? Nature 433, 585, 2005.

16. Brandenberger, R., Burger, S., Campbell, A., Fong, T., Lapinskas, E., and Rowley, J.A. Cell therapy bioprocessing. BioProcess Int 9, 30, 2011.

17. Oh, S.K.W., Chen, A.K., Mok, Y., Chen, X., Lim, U.-M., Chin, A., et al. Long-term microcarrier suspension cultures of human embryonic stem cells. Stem Cell Res 2, 219, 2009.

18. Nie, Y., Bergendahl, V., Hei, D.J., Jones, J.M., and Palecek, S.P. Scalable culture and cryopreservation of human embryonic stem cells on microcarriers. Biotechnol Prog 25, 20, 2009.

19. Chen, A.K.-L., Chen, X., Choo, A.B.H., Reuveny, S., and Oh, S.K.W. Critical microcarrier properties affecting the expansion of undifferentiated human embryonic stem cells. Stem Cell Res 7, 97, 2011.

20. Serra, M., Brito, C., Sousa, M.F.Q., Jensen, J., Tostões, R., Clemente, J., et al. Improving expansion of pluripotent human embryonic stem cells in perfused bioreactors through oxygen control. J Biotechnol 148, 208, 2010.

21. Bardy, J., Chen, A., Lim, Y.M., Wu, S., Wei, S., Weiping, H., et al. Microcarrier suspension cultures produce high yields of neural progenitor cells from human pluripotent stem cells. Tissue Eng Part C Method 19, 166, 2013.

22. Heng, B.C., Li, J., Chen, A.K.-L., Reuveny, S., Cool, S.M., Birch, W.R., et al. Translating human embryonic stem cells from 2-dimensional to 3-dimensional cultures in a defined medium on laminin- and vitronectin-coated surfaces. Stem Cells Dev 21, 1701, 2012.

23. Lock, L.T., and Tzanakakis, E.S. Expansion and differentiation of human embryonic stem cells to endoderm progeny in a microcarrier stirred-suspension culture. Tissue Eng Part A 15, 2051, 2009.

24. Chen, A., Reuveny, S., and Oh, S.K. Application of human mesenchymal and pluripotent stem cell microcarrier cultures in cellular therapy: achievements and future direction. Biotechnol Adv 2013 http://dx.doi.org/10.1016/j.biotechadv.2013.03.006

25. Yu, J., Vodyanik, M.A., Smuga-Otto, K., AntosiewiczBourget, J., Frane, J.L., Tian, S., et al. Induced pluripotent stem cell lines derived from human somatic cells. Science 318, 1917, 2007.

26. Chen, X., Chen, A., Woo, T.L., Choo, A.B.H., Reuveny, S., and Oh, S.K.W. Investigations into the metabolism of twodimensional colony and suspended microcarrier cultures of human embryonic stem cells in serum-free media. Stem Cells Dev 19, 1781, 2010.

27. Chen, A.K., Chen, X., Choo, A.B., Reuveny, S., and Oh, S.K. Expansion of human embryonic stem cells on cellulose microcarriers. Curr Protoc Stem Cell Biol 1C.11.1, 2010.

28. Choo, A.B., Tan, H.L., Ang, S.N., Fong, W.J., Chin, A., Lo, J., et al. Selection against undifferentiated human embryonic stem cells by a cytotoxic antibody recognizing podocalyxinlike protein-1. Stem Cells 26, 1454, 2008.

29. Chan, K.K.-K., Wu, S.M., Nissom, P.M., Oh, S.K.W., and Choo, A.B.H. Generation of high-level stable transgene ex- pressing human embryonic stem cell lines using chinese hamster elongation factor- $1 \alpha$ promoter system. Stem Cells Dev 17, 825, 2008.

30. Choo, A., Padmanabhan, J., Chin, A., Fong, W.J., and Oh, S.K.W. Immortalized feeders for the scale-up of human embryonic stem cells in feeder and feeder-free conditions. J Biotechnol 122, 130, 2006.

31. Arnsdorf, E.J., Tummala, P., Kwon, R.Y., and Jacobs, C.R. Mechanically induced osteogenic differentiation-the role of RhoA, ROCKII and cytoskeletal dynamics. J Cell Sci 122, 546, 2009.

32. Ohgushi, M., Matsumura, M., Eiraku, M., Murakami, K., Aramaki, T., Nishiyama, A., et al. Molecular pathway and cell state responsible for dissociation-induced apoptosis in human pluripotent stem cells. Cell Stem Cell 7, 225, 2010.

33. Riento, K., and Ridley, A.J. ROCKs: multifunctional kinases in cell behaviour. Nat Rev Mol Cell Biol 4, 446, 2003.

34. Kovács, M., Tóth, J., Hetényi, C., Málnási-Csizmadia, A., and Sellers, J.R. Mechanism of blebbistatin inhibition of myosin II. J Biol Chem 279, 35557, 2004.

35. Chen, G., Hou, Z., Gulbranson, D.R., and Thomson, J.A. Actin-myosin contractility is responsible for the reduced viability of dissociated human embryonic stem cells. Cell Stem Cell 7, 240, 2010.

36. Leung, H.W., Chen, A., Choo, A., Reuveny, S., and Oh, S. Agitation can induce differentiation of human pluripotent stem cells in microcarrier cultures. Tissue Eng Part C Method 17, 165, 2010.

37. Lecina, M., Ting, S., Choo, A., Reuveny, S., and Oh, S. Scalable platform for hESC differentiation to cardiomyocytes in suspended microcarrier cultures. Tissue Eng Part C Method 16, 1609, 2010.

38. Kehoe, D.E., Jing, D., Lock, L.T., and Tzanakakis, E.S. Scalable stirred-suspension bioreactor culture of human pluripotent stem cells. Tissue Eng Part A 16, 405, 2010.

39. Beattie, G.M., Lopez, A.D., Bucay, N., Hinton, A., Firpo, M.T., King, C.C., et al. Activin A maintains pluripotency of human embryonic stem cells in the absence of feeder layers. Stem Cells 23, 489, 2005.

40. Skottman, H., and Hovatta, O. Culture conditions for human embryonic stem cells. Reproduction 132, 691, 2006.

41. Mollamohammadi, S., Taei, A., Pakzad, M., Totonchi, M., Seifinejad, A., Masoudi, N., et al. A simple and efficient cryopreservation method for feeder-free dissociated human induced pluripotent stem cells and human embryonic stem cells. Hum Reprod 24, 2468, 2009.

42. Kurosawa, H. Application of Rho-associated protein kinase (ROCK) inhibitor to human pluripotent stem cells. J Biosci Bioeng 114, 577, 2012.

43. Gauthaman, K., Fong, C.Y., and Bongso, A. Effect of ROCK inhibitor Y-27632 on normal and variant human embryonic stem cells (hESCs) in vitro: its benefits in hESC expansion. Stem Cell Rev 6, 86, 2010.

44. Pakzad, M., Totonchi, M., Taei, A., Seifinejad, A., Hassani, S.N., and Baharvand, H. Presence of a ROCK inhibitor in extracellular matrix supports more undifferentiated growth of feeder-free human embryonic and induced pluripotent stem cells upon passaging. Stem Cell Rev Rep 6, 96, 2010.

45. Braam, S.R., Nauw, R., Ward-van Oostwaard, D., Mummery, C., and Passier, R. Inhibition of ROCK improves survival of human embryonic stem cell-derived cardiomyocytes after dissociation. Ann N Y Acad Sci 1188, 52, 2010.

46. Xu, Y., Zhu, X., Hahm, H.S., Wei, W., Hao, E., Hayek, A., et al. Revealing a core signaling regulatory mechanism for 
pluripotent stem cell survival and self-renewal by small molecules. Proc Natl Acad Sci 107, 8129, 2010.

47. Larijani, M.R., Seifinejad, A., Pournasr, B., Hajihoseini, V., Hassani, S.N., Totonchi, M., et al. Long-term maintenance of undifferentiated human embryonic and induced pluripotent stem cells in suspension. Stem Cells Dev 20, 1911, 2011.

48. Chen, V.C., Couture, S.M., Ye, J., Lin, Z., Hua, G., Huang, H.I., et al. Scalable GMP compliant suspension culture system for human ES cells. Stem Cell Res 8, 388, 2012.

49. Singh, H., Mok, P., Balakrishnan, T., Rahmat, S.N.B., and Zweigerdt, R. Up-scaling single cell-inoculated suspension culture of human embryonic stem cells. Stem Cell Res 4, 165, 2010.

50. Olmer, R., Haase, A., Merkert, S., Cui, W., Paleček, J., Ran, C., et al. Long term expansion of undifferentiated human iPS and ES cells in suspension culture using a defined medium. Stem Cell Res 5, 51, 2010.

51. Amit, M., Laevsky, I., Miropolsky, Y., Shariki, K., Peri, M., and Itskovitz-Eldor, J. Dynamic suspension culture for scalable expansion of undifferentiated human pluripotent stem cells. Nat Protoc 6, 572, 2011.

52. Steiner, D., Khaner, H., Cohen, M., Even-Ram, S., Gil, Y., Itsykson, P., et al. Derivation, propagation and controlled differentiation of human embryonic stem cells in suspension. Nat Biotechnol 28, 361, 2010.

53. Hazeltine, L.B., Selekman, J.A., and Palecek, S.P. Engineering the human pluripotent stem cell microenvironment to direct cell fate. Biotechnol Adv [Epub ahead of print]; DOI: 10.1016/j.biotechadv.2013.03.002, 2013.

54. Peerani, R., Rao, B.M., Bauwens, C., Yin, T., Wood, G.A., Nagy, A., et al. Niche-mediated control of human embryonic stem cell self-renewal and differentiation. EMBO J 26, 4744, 2007.

55. Nelson, C.M., Jean, R.P., Tan, J.L., Liu, W.F., Sniadecki, N.J., Spector, A.A., et al. Emergent patterns of growth controlled by multicellular form and mechanics. Proc Natl Acad Sci U S A 102, 111594, 2005.

56. Daley, W.P., Peters, S.B., and Larsen, M. Extracellular matrix dynamics in development and regenerative medicine. J Cell Sci 121, 255, 2008.

57. McBeath, R., Pirone, D.M., Nelson, C.M., Bhadriraju, K., and Chen, C.S. Cell shape, cytoskeletal tension, and RhoA regulate stem cell lineage commitment. Dev Cell 6, 483, 2004.

58. Sart, S., Errachid, A., Schneider, Y.-J., and Agathos, S.N. Modulation of mesenchymal stem cell actin organization on conventional microcarriers for proliferation and differentiation in stirred bioreactors. J Tissue Eng Regen Med 7, 537, 2013.
59. Clark, K., Langeslag, M., Figdor, C.G., and van Leeuwen, F.N. Myosin II and mechanotransduction: a balancing act. Trends Cell Biol 17, 178, 2007.

60. Mammoto, A., and Ingber, D.E. Cytoskeletal control of growth and cell fate switching. Curr Opin Cell Biol 21, 864, 2009.

61. Assoian, R.K., and Klein, E.A. Growth control by intracellular tension and extracellular stiffness. Trends Cell Biol 18, 347, 2008.

62. Ohgushi, M., and Sasai, Y. Lonely death dance of human pluripotent stem cells: ROCKing between metastable cell states. Trends Cell Biol 21, 274, 2011.

63. Krawetz, R.J., Li, X., and Rancourt, D.E. Human embryonic stem cells: caught between a ROCK inhibitor and a hard place. BioEssays 31, 336, 2009.

64. Datta, N., Pham, Q., Sharma, U., Sikavitsas, V.I., Jansen, J.A., and Mikos, A.G. In vitro generated extracellular matrix and fluid shear stress synergistically enhance 3D osteoblastic differentiation. Proc Natl Acad Sci U S A 103, 2488, 2006.

65. Tseng, P.-C., Young, T.-H., Wang, T.-M., Peng, H.-W., Hou, S.-M., and Yen, M.-L. Spontaneous osteogenesis of MSCs cultured on 3D microcarriers through alteration of cytoskeletal tension. Biomaterials 33, 556, 2012.

66. Teramura, T., Takehara, T., Onodera, Y., Nakagawa, K., Hamanishi, C., and Fukuda, K. Mechanical stimulation of cyclic tensile strain induces reduction of pluripotent related gene expressions via activation of Rho/ROCK and subsequent decreasing of AKT phosphorylation in human induced pluripotent stem cells. Biochem Biophys Res Commun 417, 836, 2012.

Address correspondence to: Allen Kuan-Liang Chen, PhD Stem Cell Group

Bioprocessing Technology Institute Agency for Science, Technology and Research ( $A^{*}$ STAR)

20 Biopolis Way, \#06-01 Centros Singapore 138668 Singapore

E-mail: allen_chen@bti.a-star.edu.sg

Received: March 25, 2013

Accepted: June 14, 2013

Online Publication Date: July 25, 2013 